\title{
CRIANÇA KAIOWÁ SURDA E SUA COMUNICAÇÃO NA FAMÍLIA E NA ESCOLA ${ }^{1}$
}

\author{
Kaiowá deaf child and their comunication with the family
}

And at the school

El niño kaiowá sordo y su comunicación en la familia y en la escuela

\author{
Juliana Maria da Silva Lima ${ }^{2}$ \\ Marilda Bruno ${ }^{3}$
}

\begin{abstract}
Resumo
O presente artigo é um recorte da dissertação de mestrado em educação e apresenta uma visão geral sobre a comunicação da criança Kaiowá surda no contexto familiar e escolar das Aldeias Bororó e Jaguapiru, em Dourados, MS. Trata-se de uma pesquisa qualitativa, de cunho etnográfico fundamentada nos Estudos Culturais e nas premissas do desenvolvimento ecológico de Bronfenbrenner (1996). Os procedimentos e os instrumentos para coleta e análise de dados envolveram: a observação participante, o registro no diário de campo e a entrevista semiestruturada. Participaram deste estudo cinco crianças indígenas da etnia Kaiowá, sendo uma com diagnóstico médico de surdez e as outras, apenas pela observação funcional. Os resultados revelaram que: a) a criança Kaiowá surda interage e se comunica por meio de sinais icônicos; b) ocupa um lugar de invisibilidade, perpassado pelas representações sociais da impossibilidade da fala, da aquisição de conhecimento e assimilação da cultura tradicional; c) as práticas comunicativas não favorecem a constituição das identidades surdas e indígenas. Nesses contextos, ressalta-se a necessidade de estabelecer trocas de saberes entre os envolvidos com a aprendizagem das crianças indígenas surdas, além de potencializar espaços para o desenvolvimento linguístico, cognitivo e sociocultural.
\end{abstract}

Palavras-chave: Língua de sinais. Surdez. Educação Indígena.

\section{Abstract}

This article is an snippet from master's thesis in education and presents a global vision about the Kaiowá deaf child communication within the Family and school fom Bororó and Jaguapiru thorp in Dourados, Mato Grosso do Sul. It is aboute a qualitative research, an ethnographic essence based on

\footnotetext{
* Dissertação defendida em 2013, no Programa de Pós-graduação em Educação da Faculdade de Educação da Universidade Federal da Grande Dourados. Pesquisa financiada PROGESP/CAPES.

${ }^{2}$ Doutoranda do Programa de Pós-graduação de Educação pela Faculdade de Educação- UFGD (2015 em andamento). Participante-pesquisadora do GEPETIC - Grupo de Estudos e Pesquisas em Educação e Tecnologias da Informação e Comunicação. Mestre em Educação pelo Programa de Pós-graduação de Educação da Faculdade de Educação- UFGD. Licenciatura em Educação Física - Unigran Centro Universitário da Grande Dourados (2001-2004). Bacharelado em Letras - Libras - UFSC/Pólo UFGD (2008-2012). Especialização em Educação Especial (2005) ESAP Instituto de Estudos Avançados e Pós-Graduação. Especialização em Libras docência e intérprete (2009) - FINAV Faculdades Integradas de Naviraí. Proficiente em Tradução e Interpretação da Língua Brasileira de Sinais (Libras) - Língua Portuguesa - Libras - nível superior (PROLIBRAS-UFSCMEC) e no Uso e Ensino de Libras (PROLIBRAS-MEC-INES-UFSC).

${ }^{3}$ Professora associada, aposentada na Universidade Federal da Grande Dourados (UFGD). Docente do Programa de Pós Graduação em Educação da Faculdade de Educação. Pesquisadora da Linha Educação e Diversidade. Doutorado em Ensino da Educação Brasileira pelo Programa de Pós-graduação da Universidade Estadual Paulista - Júlio de Mesquita Filho (UNESP). Mestre em Educação pelo Programa de Pós-graduação pela Universidade Católica Dom Bosco (UCDB). Especialização em Intervenção Precoce na Fundação Oftalmológica de Bueno Aires (Argentina). Graduação em Pedagogia com Habilitação em Educação Especial (Ensino do deficiente Visual) pela Universidade de São Paulo (USP). Graduação em Letras pela Universidade do Sagrado Coração (USC).
} 
Cultural Studies and ecological development of Bronfenbrenner (1996). The procedures and tools for data collection and analysis involved: participant observation, the record in the field diary and a semistructured interview. The study included five indigenous children Kaiowá ethnic group, one with a medical diagnosis of deafness and the other, just with functional observation. The results showed that: a) the Kaiowá deaf child interacts and communicates through iconic signals; b) occupies a place of invisibility, permeated by social representations of the impossibility of speech, knowledge acquisition and assimilation of traditional culture; c) the communicative practices do not favor the formation of deaf and indigenous identities. In these contexts, the study emphasizes the necessity to establish the changes of knowledge among those involved in the learning of deaf indigenous children, and enhance spaces for linguistic, cognitive and socio-cultural development.

KEYWORDS: Sign language. Deafness. Indigenous Education.

\section{Resumen}

El presente artículo es un recorte de la tesis de maestría en educación y presenta una visión general sobre la comunicación del niño Kaiowá sordo en el contexto familiar y escolar de las comunidades Bororó y Jaguapirú, en Dourados, MS. Se trata de una investigación cualitativa etnográfica fundamentada en los Estudios Culturales y en las premisas del desarrollo ecológico de Bronfenbrenner (1996). Los procedimientos y los instrumentos para colecta y análisis de datos involucraron: la observación participante, el registro en el diario de campo y la entrevista semiestructurada. Participaron de este estudio cinco niños indígenas de la etnia Kaiowá, siendo una con diagnóstico médico de sordera y las otras, apenas por la observación funcional. Los resultados revelaron que: a) el niño Kaiowá sorda interacciona y se comunica por medio de señales icónicos; b) ocupa un lugar de invisibilidad, atravesado por las representaciones sociales de la imposibilidad de la habla, de la adquisición de conocimiento y asimilación de la cultura tradicional; c) las prácticas comunicativas no favorecen la constitución de las identidades sordas e indígenas. En esos contextos, se resalta la necesidad de establecer cambios de conocimientos entre los involucrados con el aprendizaje de los niños indígenas sordos, más allá de potenciar espacios para el desarrollo lingüístico, cognitivo y sociocultural.

PALABRAS CLAVE: Lengua de señas. Sordera. Educación Indígena.

\section{INTRODUÇÃO}

A Educação Escolar Indígena começa a estabelecer um diálogo com a Educação Especial, a partir da Política Nacional de Educação Especial na Perspectiva da Educação Inclusiva (BRASIL, 2008), que delibera o direito ao Atendimento Educacional Especializado aos povos indígenas. Esse documento assegura além de assegurar o acesso e a permanência da população com deficiência em todos os níveis de ensino, também evidencia as condições de igualdade de oportunidades, independentemente das diferenças étnicas, linguísticas, intelectuais entre outras.

Através da Resolução $n^{0}$ 5/2012 que estabelece novas Diretrizes Curriculares Nacionais para a Educação Escolar Indígena na Educação Básica, institui ao Ministério da Educação a competência para diagnosticar a demanda por Educação Especial nas comunidades indígenas, bem como, criar uma política nacional de atendimento aos estudantes indígenas que necessitem de atendimento educacional. (BRASIL, 2012, art. 11, § $1^{\circ}$ ).

Ao explorar esse assunto, questões socioculturais e linguísticas vêm à tona com o intuito de dar visibilidade ao direito linguístico da população indígena, além de evitar possíveis ações e posturas colonizadoras diante dessas comunidades. É a partir dessa perspectiva que este estudo se estabelece.

Diante do exposto, cabe questionar: De que maneira a criança indígena surda interage e se comunica com outras crianças? Como se comunica e aprende no espaço familiar e 
escolar? Assim, o objetivo deste estudo foi investigar a criança indígena surda na cultura guarani-kaiowá e suas formas de comunicação na família e na escola.

Para tanto, apresenta-se o delineamento teórico-metodológico da pesquisa e uma breve contextualização sobre a criança indígena surda e por fim, são analisadas as formas de comunicação da criança Kaiowá surda nos contextos familiar e escolar.

\section{O percurso investigativo e os participantes}

A discussão sobre as diferenças culturais e linguísticas configura-se no interstício social (BHABHA, 2010) entendido como espaço de diálogo, com permanentes negociações nos locais e entre as fronteiras culturais. A relação entre família e criança surda e a relação escola e pessoa surda configura-se como um interstício social, pois se busca criança indígena surda interagir no contexto familiar e escolar.

O estudo procura articular a concepção de cultura indígena e cultura surda, entendidas como fatores que estão além da diversidade cultural, como expressão e modo de ser de um povo, e a surdez como diferença linguística. A orientação ecológica de Bronfenbrenner (1996) subsidia as análises a partir do entendimento sobre a interdependência entre o micro e o mesossistemas de que a criança indígena surda participa e a importância de suas interrelações pessoais para a constituição do Ser-índio e Ser-Surdo no contexto das culturas envolventes.

Trata-se de uma pesquisa qualitativa de cunho etnográfico, segundo Caria (2003) a etnografia possibilita a apreensão sobre o objeto, a partir do "viver dentro", firmado através da observação participante e do registro em diário de campo. O autor agrega ser essencial conhecer as diferenças culturais e as fronteiras interculturais,

Por se tratar de uma pesquisa com crianças, adotamos as orientações de Ferreira (2003) sobre como desenvolver uma pesquisa etnográfica com elas. Para isso, tomamos a postura dos adultos-investigadores diante das crianças-investigadas. A autora complementa que esse tipo de etnografia, a renegociação de papéis e reconfigurações sucessivas configuram em um processo constante de reflexão. Essa atitude pode colaborar na visualização do lugar das crianças indígenas surdas nos espaços familiar e escolar.

Ressalva-se que este estudo faz parte do projeto "Mapeamento das deficiências nas aldeias da região da Grande Dourados: um estudo sobre os impactos e as possíveis implicações para inclusão educacional", aprovado pelo Comitê de Ética da UFGD, pelas lideranças indígenas e participantes da pesquisa (familiares e professores das crianças indígenas surdas).

Participaram deste estudo cinco crianças indígenas da etnia Kaiowá, sendo uma com diagnóstico médico de surdez e as outras, apenas pela observação funcional. As crianças serão denominadas $\mathrm{C}_{1}, \mathrm{C}_{2}, \mathrm{C}_{3}, \mathrm{C}_{4}$ e $\mathrm{C}_{5}$, conforme detalhado no quadro abaixo:

Quadro 1: Identificação das crianças indígenas surdas participantes da pesquisa.

\begin{tabular}{|c|c|c|l|l|l|}
\hline $\begin{array}{c}\text { CRIANÇA/ } \\
\text { SIGLA }\end{array}$ & IDADE & SEXO & \multicolumn{1}{|c|}{$\begin{array}{c}\text { ESCOLA/ } \\
\text { SIGLA }\end{array}$} & $\begin{array}{c}\text { LOCAL ONDE } \\
\text { RESIDE }\end{array}$ & $\begin{array}{c}\text { INFORMAÇÕES } \\
\text { ADICIONAIS }\end{array}$ \\
\hline $\mathbf{C}_{\mathbf{1}}$ & 12 & $\mathrm{~F}$ & Escola A & Aldeia Bororó & $\begin{array}{l}\text { Surdez com } \\
\text { diagnóstico médico }\end{array}$ \\
\hline $\mathbf{C}_{\mathbf{2}}$ & 4 & $\mathrm{M}$ & $\begin{array}{l}\text { Frequenta a SRM } \\
\text { da escola B }\end{array}$ & Aldeia Jaguapiru & $\begin{array}{l}\text { Suspeita de surdez e } \\
\text { baixa visão, com } \\
\text { encaminhamento } \\
\text { médico }\end{array}$ \\
\hline
\end{tabular}

Educação e Fronteiras On-Line, Dourados/MS, v.7, n.19, p.38-47, jan./abr. 2017 


\begin{tabular}{|c|c|c|l|l|l|}
\hline $\mathbf{C}_{\mathbf{3}}$ & 7 & $\mathrm{M}$ & Escola B & Aldeia Jaguapiru & $\begin{array}{l}\text { Suspeita de surdez e } \\
\text { baixa visão, com } \\
\text { encaminhamento } \\
\text { médico }\end{array}$ \\
\hline $\mathbf{C}_{\mathbf{4}}$ & $\begin{array}{c}1 \text { ano e } 8 \\
\text { meses }\end{array}$ & $\mathrm{F}$ & $\begin{array}{l}\text { Observação no } \\
\text { ambiente familiar }\end{array}$ & Aldeia Jaguapiru & $\begin{array}{l}\text { Suspeita de surdez e } \\
\text { baixa visão, com } \\
\text { encaminhamento } \\
\text { médico }\end{array}$ \\
\hline $\mathbf{C}_{\mathbf{5}}$ & 10 & $\mathrm{M}$ & Escola C & Aldeia Bororó & $\begin{array}{l}\text { Nunca teve até então, } \\
\text { experiências fora do } \\
\text { seu ambiente familiar }\end{array}$ \\
\hline
\end{tabular}

Fonte: LIMA, 2013.

Observa-se que as crianças indígenas surdas selecionadas pertencem à faixa etária entre 1 ano e 8 meses e 12 anos, todas são da etnia Kaiowá. Duas são meninas e três meninos. $\mathrm{C}_{2}$ e $\mathrm{C}_{4}$ não estão matriculados na escola. $\mathrm{C}_{1}, \mathrm{C}_{3}$ e $\mathrm{C}_{5}$ frequentam escolas municipais indígenas, $\mathrm{A}, \mathrm{B}$ e $\mathrm{C}$ respectivamente. $\mathrm{C}_{2}$ frequenta a Sala de Recursos Multifuncionais (SRM) da escola B. Em relação ao diagnóstico, somente $C_{1}$ apresenta laudo médico que atesta a surdez e também é a única desse quadro que é usuária de Libras e está em fase de letramento. $\mathrm{C}_{2}$ e $\mathrm{C}_{3}$ recebem atendimento na SRM com uma professora indígena bilíngue/Libras que ensina em Língua de Sinais o conteúdo direcionado pela professora responsável da SRM na escola B. Nota-se que $\mathrm{C}_{2}, \mathrm{C}_{3}$ e $\mathrm{C}_{4}$ são irmãos e foram identificados com o auxílio de uma professora não indígena da SRM da escola $\mathrm{B}$. Registra-se poucas informações sobre o $\mathrm{C}_{5}$, pois ele havia sido matriculado recentemente na escola $\mathrm{C}$ e, por isso, o que se sabe é que ele não tem uma língua, assim como $\mathrm{C}_{2}, \mathrm{C}_{3}$ e $\mathrm{C}_{4}$. Sua interação e comunicação com os colegas na escola e em seu ambiente familiar restringem-se aos apontamentos, segundo as informações da professora $\mathrm{P}_{4}$. Essa mesma professora $\left(\mathrm{P}_{4}\right)$ também revelou informações que sustentam as discussões posteriores.

Para as entrevistas semiestruturadas, foram selecionados os familiares $\left(\mathrm{FM}_{1}, \mathrm{FP}_{1}, \mathrm{FI}_{1}\right.$, $\mathrm{FM}_{234}, \mathrm{FP}_{234}$ e $\left.\mathrm{FI}_{5}\right)$ e os professores indígenas $\left(\mathrm{P}_{1 \mathrm{~A}}, \mathrm{P}_{2 \mathrm{~A}}, \mathrm{P}_{3 \mathrm{~B}}\right.$ e $\left.\mathrm{P}_{4 \mathrm{C}}\right)$ que já atenderam ou atendem o aluno indígena surdo em sala de aula. Segue abaixo, o quadro detalhado sobre os familiares e dos professores, na sequência, que participaram desse estudo:

Quadro 2: Familiares das crianças indígenas surdas.

\begin{tabular}{|c|c|c|l|}
\hline $\begin{array}{c}\text { FAMILIAR OU } \\
\text { RESPONSÁVEL/SIGLA }\end{array}$ & IDADE & SEXO & \multicolumn{1}{|c|}{ INFORMAÇÕES ADICIONAIS } \\
\hline FM $_{\mathbf{1}}$ & 30 & $\mathrm{~F}$ & Mãe da $\mathbf{C}_{\mathbf{1}}$ \\
\hline $\mathbf{F P}_{\mathbf{1}}$ & 27 & $\mathrm{M}$ & $\begin{array}{l}\text { Pai da } \mathbf{C}_{\mathbf{1}} \\
\text { Não foi possível fazer a entrevista, pois se } \\
\text { encontrava fora do convívio social. }\end{array}$ \\
\hline $\mathbf{F I}_{\mathbf{1}}$ & 10 & $\mathrm{~F}$ & Irmã da $\mathbf{C}_{\mathbf{1}}$ \\
\hline $\mathbf{F M}_{\mathbf{2 3 4}}$ & 26 & $\mathrm{~F}$ & Mãe da $\mathbf{C}_{\mathbf{2}}, \mathbf{C}_{\mathbf{3}}, \mathbf{C}_{\mathbf{4}}$ \\
\hline $\mathbf{F P}_{\mathbf{2 3 4}}$ & 33 & $\mathrm{M}$ & Pai da $\mathbf{C}_{\mathbf{2}}, \mathbf{C}_{\mathbf{3}}, \mathbf{C}_{\mathbf{4}}$ \\
\hline $\mathbf{F I}_{\mathbf{5}}$ & 16 & $\mathrm{~F}$ & Irmã da $\mathbf{C}_{\mathbf{5}}$ \\
\hline
\end{tabular}


Fonte: LIMA, 2013.

Os familiares selecionados pertencem à faixa etária de 10 a 33 anos, compreendem a ligação familiar como mães, pais e uma irmã. Todos são da etnia Kaiowá. $\mathrm{FM}_{1}$ e $\mathrm{FP}_{1}$ são pais da $\mathrm{C}_{1} \cdot \mathrm{FP}_{1}$ não concedeu entrevista e, nesse mesmo período, agrediu fisicamente sua filha surda e separou-se de sua esposa. Encontra-se em liberdade, mas responde a processo judicial. Casou-se novamente com uma jovem indígena. $\mathrm{FM}_{1}$, aparentemente, apresenta-se triste e na espera pelo retorno de $\mathrm{C}_{1}$ que está sob custódia em um abrigo para meninas que sofreram violência doméstica. $\mathrm{FI}_{1}$ estuda na mesma escola $\mathrm{A}$ que sua irmã $\mathrm{C}_{1}$. Ela demonstrou estar com saudades da irmã surda $\left(\mathrm{C}_{1}\right)$ que está no abrigo. Também, apresentou desenvoltura para a língua de sinais, sabe alguns sinais da Libras e outros fazem parte dos sinais domésticos para comunicação no ambiente familiar. $\mathrm{O}$ casal $\mathrm{FM}_{234}$ e $\mathrm{FP}_{234}$ possuem três filhos, uma menina e dois meninos $\left(\mathrm{C}_{2}, \mathrm{C}_{3}\right.$ e $\left.\mathrm{C}_{4}\right)$, todos com encaminhamento médico por suspeita de surdez e baixa visão (informações da professora $\mathrm{P}_{1 \mathrm{~A}}$ e da professora não indígena da $\mathrm{SRM}$ da escola B). $\mathrm{FI}_{5}$ estuda na mesma escola (C) que o seu irmão $\mathrm{C}_{5}$ e, após algumas idas e vindas à escola e à casa da família, $\mathrm{FI}_{5}$ narrou informações gerais sobre $\mathrm{C}_{5}$, uma vez que a mãe e o pai (padrasto de $\mathrm{FI}_{5}$ ) não se encontravam em casa para falar sobre o filho.

Quadro 3: Educadores indígenas que trabalham ou já trabalharam com crianças indígenas surdas incluídas em classe comum.

\begin{tabular}{|c|c|c|c|c|c|}
\hline $\begin{array}{l}\text { PROFESSOR/ } \\
\text { SIGLA }\end{array}$ & $\begin{array}{l}\text { ESCOLA/ } \\
\text { ATUAÇÃO }\end{array}$ & ETNIA & SEXO & IDADE & FORMAÇÃO ACADÊMICA \\
\hline $\mathbf{P}_{1 \mathrm{~A}}$ & $\begin{array}{l}\text { Escola A; } \\
\text { Professora } \\
\text { da SRM e } \\
\text { professora } \\
\text { itinerante da } \\
\text { C }_{\mathbf{1}} \text {. }\end{array}$ & Kaiowá & $\mathrm{F}$ & 31 & $\begin{array}{l}\text { Magistério; } \\
\text { Graduação em Fisioterapia e } \\
\text { Educação Física; } \\
\text { Pós-graduação em Metodologia do } \\
\text { Ensino Superior; Libras: Docência } \\
\text { e intérprete e Educação Física } \\
\text { Escolar. }\end{array}$ \\
\hline $\mathbf{P}_{2 \mathrm{~A}}$ & $\begin{array}{l}\text { Escola A; } \\
\text { Professor do } \\
3^{\circ} \text { ano. }\end{array}$ & Kaiowá & $\mathrm{M}$ & 29 & $\begin{array}{l}\text { Magistério Ara Vera; } \\
\text { Cursa o } 3^{\circ} \text { semestre do Teko } \\
\text { Arandu. }\end{array}$ \\
\hline $\mathbf{P}_{3 \mathrm{~B}}$ & $\begin{array}{l}\text { Escola } \mathbf{B} ; \\
\text { Professora } \\
\text { do } 1^{\circ} \text { ano. }\end{array}$ & Terena & $\mathrm{F}$ & 42 & $\begin{array}{l}\text { Magistério; } \\
\text { Graduação em Pedagogia; } \\
\text { Pós-graduação em Psicopedagogia. }\end{array}$ \\
\hline $\mathbf{P}_{4 \mathrm{C}}$ & $\begin{array}{l}\text { Escola } \mathbf{C} ; \\
\text { Professora } \\
\text { do } 1^{\circ} \text { ano. }\end{array}$ & Kaiowá & $\mathrm{F}$ & 36 & $\begin{array}{l}\text { Magistério; } \\
\text { Magistério Ara Vera; } \\
\text { Cursa o } 8^{\circ} \text { semestre do curso de } \\
\text { licenciatura Teko Arandu. }\end{array}$ \\
\hline
\end{tabular}

Fonte: LIMA, 2013.

A idade dos professores indígenas varia entre 29 e 42 anos. Todos os professores apresentaram experiência com o aluno surdo em sala de aula. $\mathrm{P}_{3 \mathrm{~B}}$ e $\mathrm{P}_{4 \mathrm{C}}$ demonstram inexperiência em relação à Educação de Surdos e aparentemente desconhecem a Libras. Pautam a comunicação dos surdos com o uso de mímica e/ou gestos aleatórios. Em relação à formação inicial dos professores indígenas, observa-se que todos cursaram o magistério superior, sendo dois com habilitação específica para educação indígena e um com formação em Libras. Durante a formação continuada, tiveram a oportunidade de participar de alguns cursos direcionados à Educação Especial oferecidos pela Secretaria Municipal de Educação de Dourados (SEMED). Observa-se que todos os professores possuem formação para o magistério e apenas dois têm a formação específica para a educação indígena Licenciatura Teko Arandu e Ara Vera, os mesmos que trabalham com português/guarani nas séries iniciais. 
$\mathrm{P}_{1 \mathrm{~A}}$ e $\mathrm{P}_{3 \mathrm{~B}}$ possuem especialização e apenas $\mathrm{P}_{1 \mathrm{~A}}$ tem especialização na área da surdez com 360h de Libras; $\mathrm{P}_{3 \mathrm{~B}}$ e $\mathrm{P}_{4 \mathrm{C}}$ não tiveram nenhuma formação em Libras ou para a educação de pessoas surdas; já o $\mathrm{P}_{2 \mathrm{~A}}$ teve uma formação com carga horária de 40 horas de Libras, não sendo suficiente para a comunicação nessa língua. Nota-se que todos os professores indígenas selecionados para esta pesquisa, durante a formação acadêmica e continuada, tiveram a oportunidade de participar de alguns cursos direcionados à Educação Especial oferecidos pela SEMED.

Complementando as informações pertinentes ao ambiente escolar: $\mathrm{P}_{1 \mathrm{~A}}$ é professora bilíngue/Libras desde 2009 da $\mathrm{C}_{1}$, na escola A. Também, atuou como professora regente de 2007 a 2010 de duas crianças surdas (atualmente, com 15 e 19 anos) na escola C. $\mathrm{P}_{2 \mathrm{~A}}$, em 2009, foi o professor regente do terceiro ano do Ensino Fundamental em que $\mathrm{C}_{1}$ estava incluída, na escola $\mathrm{A} . \mathrm{P}_{3 \mathrm{~B}}$ é professora regente do primeiro ano do Ensino Fundamental em que $\mathrm{C}_{3}$ está incluído, na escola $\mathrm{B}$. $\mathrm{P}_{4 \mathrm{C}}$ é professora regente do primeiro ano do Ensino Fundamental em que $\mathrm{C}_{5}$ está incluído, na escola $\mathrm{C}$.

Os dados coletados foram sistematicamente registrados em diário de campo, fotografias e gravação em áudio. O diálogo entre esses dados empíricos e a fundamentação teórica dos contextos naturais de Bronfenbrenner e os Estudos Culturais contribuíram para o tratamento e a análise dos dados. Na sequência foi realizada a triangulação dos dados, conforme Triviños (1987), a fim de subsidiar a máxima descrição, explicação e compreensão do objeto de estudo.

\section{Criança Kaiowá surda e a comunicação no contexto familiar}

O ponto inicial do estudo consiste em compreender as formas de comunicação e interação entre a criança surda e a comunidade indígena, cujas configurações interferem diretamente no processo de pertencimento da criança indígena surda na família e na escola.

Em relação aos aspectos comunicativos, de acordo com Silva (2003), o surdo poderá se manifestar (opiniões, ideias, sentimentos, entre outros) através de uma linguagem interiorizada. Todavia, será necessária qualidade nessa interação família-criança surda para a composição da auto-imagem do surdo.

Conforme as pesquisas de Quadros (1997) esclarecem sobre a espontaneidade na aquisição de uma língua de sinais pautada nos sinais icônicos que transparecem a representatividade de forma ou ação. Entretanto, quando a criança surda não é exposta a língua gesto-visual, ela utilizará de recursos como apontamentos e esses sinais manuais para estabelecer uma comunicação imediatista, num grau superficial dos assuntos selecionados.

Sobre esta afirmação, o pai de três crianças Kaiowá surdas $\left(\mathrm{FP}_{234}\right)$ afirma que:

Eles conversam na senha. Eles se entendem. Ela também entende [...]

Eu não converso muito com eles, não. [...]

Porque eu não tenho tempo, saio pra lá e pra cá. Eu saio de casa assim, para ajudar eles. E a dificuldades deles é só isso mesmo. [...]

É. Aí ele usa senha. [...]

Conversam que normalmente, igual um irmão ou irmã, toda criança consegue. Mas, agora eu que sou pai, eu não consigo porque não fui eu que ensinei. Eles sozinho que fazem. Eu nunca converso com as pessoas deficientes assim, da fala assim, mudo.

Possivelmente os familiares conhecem as concepções sobre surdez compartilhadas pela comunidade. Sendo, "a surdez para as comunidades Guarani tradicionais representa um fator determinante na constituição dos sujeitos. Sem a possibilidade de comunicação e 
expressão por meio da palavra e da fala, o sujeito surdo não é reconhecido pela comunidade como pertencente a ela" (BRUNO; COELHO, 2012, p. 16).

Com base nas representações da cultura guarani-kaiowá sobre a surdez, as observações de campo e os relatos denotam que o processo comunicativo e de interação estabelecido entre as crianças indígenas surdas e seus familiares são comunicações restritas, marcadas por preocupações, superproteção, e utilizadas de forma aligeirada e instrumental para atender a necessidades momentâneas, que não contribuem para apreensão do mundo, desenvolvimento da linguagem, constituição de identidade, e fundamentalmente para assimilação das peculiaridades culturais em que estão inseridas. Relaciona-se a importância da relação e interação de Bronfenbrenner (1996), que discorre sobre a adaptação progressiva e recíproca entre a pessoa desenvolvente e o ambiente imediato, sendo a relação e a interação entre o sujeito ativo e o ambiente os principais efeitos da ecologia do desenvolvimento humano.

Criança Kaiowá surda e a comunicação no contexto escolar

No ambiente educacional, os educadores indígenas compartilham da aceitação do profissional intérprete de língua de sinais em suas salas de aula e esclarecem que esta possibilidade contribui tanto para a inclusão do aluno surdo no espaço escolar como, também, para a comunicação professor-aluno surdo. Todos consideram a língua de sinais importante no processo de ensino-aprendizagem, mas muitos desconhecem essa língua.

$\mathrm{O}$ professor $\mathrm{P}_{2 \mathrm{~A}}$ argumenta sobre a necessidade de aprender a Libras para se aproximar do aluno surdo.

\begin{abstract}
Então, eu senti certa dificuldade primeiro, porque o professor ele tem que entender primeiro, tem que estudar essa Língua de Sinais, para poder dominar aí como um intérprete ou seja, um professor que entende, para o intérprete é comum isso aí. Eu acho que tem que ser assim adaptar para o mundo dele também. Eu acho que avalia bem mais assim, a gente entende quais foram os objetivos da aula. Eu acho que o professor tem que entender para elaborar material e entender também a Língua de Sinais, saber conversar também para ter entendimento melhor. Eu acho que todo professor tem que entender, ter prática tanto da Libras quanto do Braile também. O Braile para o cego.
\end{abstract}

Coelho (2011) também enfatiza em sua dissertação que a dificuldade dos professores em se comunicar com os alunos indígenas surdos, acontece por falta de conhecimento sobre a língua gesto-visual ou de formação específica, sendo uma comunicação limitada pela diferença linguística.

A narrativa da professora $\mathrm{P}_{3 \mathrm{~B}}$ demonstra insegurança quanto à sua comunicação com $\mathrm{o}$ surdo e apresenta desmotivação em aprender a língua de sinais, e por isso afirma a importância do profissional intérprete de Libras em suas aulas. No caso, "o intérprete educacional é aquele que atua como profissional intérprete de língua de sinais na educação" (BRASIL, 2004, p. 59). Em suma, reflete-se sobre o papel do intérprete educacional, de modo que o professor não transfira a responsabilidade da aprendizagem do aluno surdo ao intérprete de Libras. Para isso, a lei no 12.319 , de $1^{\circ}$ de setembro de 2010 , regulamenta a profissão de tradutor e intérprete da Libras. Em linhas gerais, a lei define sua competência nas duas línguas envolvidas, a língua de sinais e a Língua Portuguesa, tendo como atribuições a efetivação da acessibilidade comunicativa nos espaços em que estiverem presentes as pessoas surdas.

Os professores indígenas que apresentam pouco ou nenhum conhecimento acerca da Libras utilizam-se de apontamentos e da criação de sinais icônicos para suprir a necessidade momentânea de comunicação, conforme se observou. Notou-se, também, que esses gestos com construções simbólicas não são utilizados em outra situação, pois são esquecidos por ambos.

Santana et. al. (2008) retratam que o gesto configura em uma mediação comunicativa, revelando um estágio intermediário para a aquisição tanto da linguagem oral quanto da língua 
de sinais. As autoras afirmam que os gestos fazem parte dos processos simbólicos iniciais da criança surda e da criança ouvinte. Entretanto, na área da surdez, a discussão sobre gestos torna-se mais complexa, pois a criança surda filha de pais ouvintes cria um sistema de comunicação particular. Compreender esses sinais domésticos, desenvolvidos no ambiente familiar, sugere o auxílio na compreensão articulada ao espaço escolar.

Nesse sentido, o estudo de Vilhalva (2012) procurou mapear as línguas de sinais indígenas no estado de Mato Grosso do Sul (MS), possibilitando o registro de uma língua de sinais emergente. Segundo a autora, essa língua de sinais emergente está em processo de desenvolvimento, pois surge a partir da necessidade imediata de cada sujeito surdo se comunicar. Vilhalva acrescenta outras denominações para esses sinais, tais como: gestos caseiros ou práticas linguísticas, e, em nota de rodapé (em livro resultante da dissertação em Linguística), justifica a opção por utilizar o termo "sinais emergentes" por mapear uma Língua de Sinais em desenvolvimento nas comunidades indígenas do estado do MS (VILHALVA, 2012). Em suas conclusões, a autora destaca a necessidade de:

[...] buscar o conhecimento das línguas usadas pelos índios surdos, mesmo que elas apresentem inúmeras especificidades, seja pelo fato de os índios estarem em espaços diferentes dentro das terras indígenas, seja pelo fato de cada família ter seus sinais emergentes ou mesmo estar adquirindo a Libras. Afinal, somente assim poderemos contribuir com os direitos humanos dos surdos e com a produção surda nos aspectos linguísticos, culturais e de identidade, já que existe um "ser surdo" que aprende o mundo pela visão (VILHALVA, 2012, p. 146-147, grifos da autora).

Busca-se no conceito de cultura como "teias" do antropólogo Clifford Geertz (2008), para visualizar que essas teias incorporam e se modificam de acordo com as necessidades locais ou dos próprios indivíduos. $\mathrm{O}$ autor revela: “[...] assumo a cultura como sendo essas teias e a sua análise; portanto, não como uma ciência experimental em busca de leis, mas como uma ciência interpretativa, à procura do significado" (GEERTZ, 2008, p. 4). Ponderações acerca das teias culturais aparentemente nos auxiliam a conhecer os sujeitos da pesquisa e a interpretar as formas de comunicação, vislumbrando as especificidades da Educação Escolar Indígena e da Educação de Surdos.

\section{CONSIDERAÇÕES FINAIS}

Esta pesquisa focalizou alguns aspectos das formas de interação e comunicação da criança indígena surda produzidas na articulação entre as diferenças culturais e linguísticas.

$\mathrm{O}$ percurso investigativo e as discussões teórico-conceituais adotados permitiram observar como os familiares e os professores indígenas (micro e mesossistemas) lidam com o fenômeno inusitado da surdez, em termos de atitudes diante da diferença linguística e cultural nas comunidades estudadas.

A criança indígena surda ainda ocupa um lugar de invisibilidade na cultura guaranikaiowá, transcorrido nas narrativas dos participantes a impossibilidade da fala, da aquisição de conhecimento e assimilação da cultura tradicional.

No geral, as práticas comunicativas configuram-se de modo rudimentar. Sendo que, os gestos/as senhas e os poucos sinais da Libras aprendidos na família e na escola não favorecem à criança Kaiowá surda constituir as suas identidades surdas e indígenas. Para tanto, o estudo evidencia a necessidade de espaços que possibilitem constantes negociações e traduções, permitindo assim que as crianças indígenas surdas possam desenvolver sua língua, adquirir conhecimentos e ter participação sociocultural. 


\section{REFERÊNCIAS}

BHABHA, H. K. O Local da Cultura. Tradução de Myriam Ávila, Eliana Lourenço de Lima Reis e Gláucia Renate Gonçalves. Belo Horizonte: Editora UFMG, 2010.

BRASIL. Casa Civil. Subchefia para assuntos jurídicos. Lei $n^{\circ} 12.319$, de 01 de setembro de 2010, que regulamenta a profissão de tradutor e intérprete da Libras. Disponível em: <http://www.planalto.gov.br/ccivil_03/_Ato2007-2010/2010/Lei/L12319.htm>. Acesso em: 20 set. 2012.

.Ministério da Educação. Política Nacional de Educação Especial na Perspectiva da Educação Inclusiva (2008). Disponível em

<http://portal.mec.gov.br/arquivos/pdf/politicaeducespecial.pdf>. Acesso em: 12 ago. 2011.

. Resolução CNE/CEB n ${ }^{0} 5$, de 22 de junho de 2012. Define Diretrizes Curriculares Nacionais para a Educação Escolar Indígena na Educação Básica. Brasília: MEC/CNE/CEB, 2012.

BRONFENBRENNER, U. A ecologia do desenvolvimento humano: experimentos naturais e planejados. Tradução de Maria Adriana Veríssimo Veronese. Porto Alegre: Artes Médicas, 1996.

BRUNO, M. M. G; COELHO, L. L. A constituição do sujeito surdo na cultura GuaraniKaiowá: os processos próprios de interação e comunicação na família e a escola. In: $35^{\text {a }}$ REUNIÃO ANUAL DA ANPED. Trabalhos GT 15 - Educação Especial. Centro de Convenções do Hotel Armação, Porto de Galinhas/PE, 21 a 24 out. 2012. Disponível em: <http://35reuniao.anped.org.br/images/stories/trabalhos/GT15\%20Trabalhos/GT152510_int.pdf $>$. Acesso em: 10 fev. 2013.

CARIA, T. H. Introdução: a construção etnográfica do conhecimento em Ciências Sociais: reflexividade e fronteiras. In: Porto: Afrontamento, 2003. p. 9-20. (Org.). Experiência Etnográfica em Ciências Sociais.

COELHO, L. L. A Constituição do Sujeito Surdo na Cultura Guarani-Kaiowá: os processos próprios de interação e comunicação na família e na escola. 2011. 125 f. Dissertação (Mestrado em Educação) - Programa de Pós-Graduação em Educação. Universidade Federal da Grande Dourados, ourados/MS, 2011.

FERREIRA, M. Capítulo 8: Os estranhos "saberes" da perplexidade numa etnografia com crianças em Jardim de Infância. In: CARIA, T. H. (Org.). Experiência Etnográfica em Ciências Sociais. Porto: Afrontamento, 2003. p. 150-166.

GEERTZ, C. A interpretação das culturas. Rio de Janeiro: LTC, 2008.

LIMA, J. M. da S. A criança indígena surda na cultura guarani-kaiowá: um estudo sobre as formas de comunicação e inclusão na família e na escola. Dourados, 2013. 123 f. Dissertação (Mestrado em Educação) - Faculdade de Educação, Universidade Federal da Grande Dourados.

QUADROS, R. M. de. Educação de Surdos: a aquisição da linguagem. Porto Alegre: Artmed, 1997. 
SANTANA, A. P. et al. O estatuto simbólico dos gestos no contexto da surdez. Psicologia em Estudo, Maringá, v. 13, n. 2, p. 297-306, abr./jun. 2008. Disponível em:

<http://www.scielo.br/pdf/pe/v13n2/a12v13n2.pdf>. Acesso em: 12 ago. 2012.

SILVA, A. B. de P. e. Surdez, Inteligência e Afetividade. In: SILVA, I. R.; KAUCHAKJE, S.; GESUELI, Z. M. (Orgs.). Cidadania, Surdez e Linguagem: Desafios e realidades. São Paulo: Plexus, 2003. p. 89-97.

TRIVIÑOS, A. N. S. Introdução à pesquisa em Ciências Sociais. A pesquisa qualitativa em educação. São Paulo: Atlas, 1987.

VILHALVA, S. Índios Surdos: Mapeamento das Línguas de Sinais de Mato Grosso do Sul. Coleção Cultura e Diversidade - Série Índio Surdo. Petropólis/RJ: Arara Azul, 2012. 159 p.

Recebido 15/04/2015

Aprovado 11/2016 